\title{
Penerapan Modified Vogel's Approximation Method (Mvam) Untuk Meminimumkan Biaya Transportasi (Studi Kasus: Pabrik Tahu Taufik)
}

\author{
Marie Afiani $^{1 *}$, Susi Setiawani ${ }^{2 *}$, Toto Bara Setiawan ${ }^{3 *}$
}

\begin{abstract}
This research aims to determine the tofu product distribution transportation model at Taufik Tofu Factory. This type of research is applied research with a quantitative approach. The method used to solve transportation problems in this study is the Modified Vogel's Approximation Method (MVAM) and optimized using the Modified Distribution (MODI) method. The results of this study indicate that the application of MVAM at the Taufik Tofu Factory provides a more minimum solution for calculating transportation costs, both in equilibrium and non-equilibrium problems. MVAM provides the same transportation costs as the optimal solution for the simplex method, which is equal to Rp1.164.911,00 for equilibrium problems and Rp2.176.838,00 for unequal problems. These results have been tested for optimism using MODI and better than the real cost calculations issued by the factory.
\end{abstract}

Keywords: Modified Vogel's Approximation Method, transportation, distribution.

\begin{abstract}
Abstrak
Penelitian ini bertujuan untuk menentukan model transportasi distribusi produk tahu di Pabrik Tahu Taufik. Jenis penelitian ini adalah penelitian terapan dengan pendekatan kuantitatif. Metode yang digunakan untuk menyelesaikan permasalahan transportasi pada penelitian ini adalah Modified Vogel's Approximation Method (MVAM) dan dioptimalisasi menggunakan metode Modified Distribution (MODI). Hasil dari penelitian ini menunjukkan bahwa penerapan MVAM di Pabrik Tahu Taufik memberikan solusi perhitungan biaya transportasi yang lebih minimum, baik pada permasalahan setimbang maupun tidak setimbang. MVAM memberikan biaya transportasi sama dengan solusi optimal metode simpleks yaitu sebesar $R p 1.164 .911,00$ untuk permasalahan setimbang dan $R p 2.176 .838,00$ untuk permasalahan tidak setimbang. Hasil tersebut telah teruji keoptimalannya menggunakan MODI dan lebih baik daripada perhitungan biaya riil yang dikeluarkan oleh pabrik.
\end{abstract}

Kata Kunci: Modified Vogel's Approximation Method, transportasi, pendistribusian.

\section{Pendahuluan}

Pendistribusian adalah kegiatan yang bertujuan untuk memasarkan suatu barang atau jasa agar sampai kepada konsumen sehingga penggunaannya sesuai dengan yang dibutuhkan [5]. Proses distribusi merupakan satu hal yang perlu diperhatikan karena pada proses tersebut

${ }^{*}$ Program Studi Pendidikan Matematika, Universitas Jember

Email: ${ }^{1}$ marieafiani25@gmail.com, ${ }^{2}$ setiawanisusi@gmail.com, ${ }^{3}$ totobara.fkip@unej.ac.id 
memerlukan biaya transportasi yang tidak sedikit, sehingga untuk meminimumkan biaya transportasi distribusi diperlukan strategi yang tepat yaitu dengan menerapkan model transportasi. Model transportasi membahas pendistribusian produk dari sumber ke tempat tujuan dengan tujuan untuk menentukan pola pendistribusian yang dapat meminimumkan biaya total distribusi dalam pemenuhan batas penawaran dan permintaan [4]. Ada beberapa metode untuk menyelesaiakan permasalahan transportasi, namun seiring dengan berkembangnya ilmu pengetahuan dan teknologi terdapat metode baru dalam menyelesaikan permasalahan transportasi, metode tersebut adalah Modified Vogel's Approximation Method (MVAM). MVAM merupakan metode yang memodifikasi metode solusi awal Vogel's Approximation Method (VAM) [3]

Penelitian sebelumnya telah dilakukan M. Wali Ullah, dkk [3] yang membandingkan metode transportasi Modified Vogel's Approximation Method (MVAM) dengan North West Corner Method (NWCM), Least Cost Method (LCM), dan Vogel'S Approximation Method (VAM). Analisisnya menghasilkan bahwa MVAM memberikan solusi awal yang lebih optimal dibandingkan dengan NCM, LCM, dan VAM. Lenti Amelia [1] mengkaji metode transportasi Modified Vogel's Approximation Method (MVAM) dan Improved Zero Point Method (IZPM) untuk permasalahan setimbang dan tidak setimbang. Pada penelitiannya diperoleh hasil bahwa metode MVAM menghasilkan solusi yang lebih optimal dibandingkan dengan metode IZPM, baik pada saat data seimbang maupun data tidak seimbang.

Berdasarkan beberapa penelitian yang telah dilakukan sebelumnya, maka pada penelitian ini akan menerapkan metode transportasi Modified Vogel's Approximation Method (MVAM) pada perhitungan biaya transportasi distribusi produk dalam permasalahan di kehidupan sehari-hari untuk meminimumkan biaya transportasi distribusi yang dikeluarkan di Pabrik Tauhu Taufik.

\section{Metode Penelitian}

Model transportasi pada penelitian ini digunakan untuk meminimumkan biaya bahan bakar minyak pada transportasi yang digunakan untuk mendistribusikan produk tahu dari pabrik ke konsumen yang berada di beberapa pasar, sedangkan fungsi kendala yang akan digunakan pada penelitian ini adalah biaya transportasi pengiriman produk per papan pada satu pasar dari pabrik ke pasar yang dituju. Pada penelitian ini menggunakan sumber $(i)$ yang merupakan jenis kendaraan, tujuan $(j)$ yang merupakan pasar di lima daerah Kabupaten Jember, $a_{i}$ adalah jumlah kapasitas persediaan produk tahu per papan yang diangkut dalam satu minnggu, $b_{j}$ adalah jumlah permintaan produk tahu per papan pada satu pasar dalam satu minggu, $c_{i j}$ adalah biaya bahan bakar minyak pada setiap transportasi yang digunakan saat pendistribusian produk tahu selama satu minggu, sedangkan $x_{i j}$ adalah banyaknya produk tahu per papan yang diangkut dari sumber ke tujuan.

Data yang digunakan pada penelitian ini adalah data primer dan data sekunder. Data primer berupa jenis transportasi yang digunakan dalam pendistribusian, biaya transportasi, keuntungan penjualan, kapasitas pengiriman produk, banyaknya persediaan, dan permintaan 
produk dalam satu minggu. Data sekunder berupa jarak tempuh dari pabrik ke tiap pasar yang diperoleh dari Google Maps.

Langkah-langkah penelitian yang dilakukan pada penelitian ini adalah sebagai berikut.

1. Membuat instrumen penelitian sebagai bahan wawancara.

2. Mengumpulkan data.

3. Menganalisis data.

4. Menghitung biaya tetap.

5. Menghitung biaya tidak tetap.

6. Menghitung biaya per papan tahu.

7. Membuat model transportasi.

8. Menyelesaikan model transportasi menggunakan MVAM.

9. Menguji keoptimalan dari hasil perhitungan MVAM dengan MODI.

10. Menyelesaikan model transportasi menggunakan metode Simpleks.

11. Menganalisis hasil perhitungan dari solusi MVAM dan MODI, metode Simpleks, dan biaya yang dikeluarkan oleh perusahaan.

12. Menarik kesimpulan.

\section{Hasil Penelitian}

Berdasarkan hasil penelitian dan analisis, alat transportasi yang digunakan untuk mendistribusikan produk adalah Pick Up A dan Pick Up B dengan kapasitas angkut dari masing-masing kendaraan sebanyak 212 papan tahu. Berdasarkan data yang diperoleh dari pabrik menyatakan bahwa tidak semua jenis kendaraan mendistribusikan produk ke semua pasar yang sama tetapi ada beberapa yang tidak didistribusikan. Oleh karena itu selain membuat model transportasi yang disesuaikan dengan pendistribusian dari pabrik, pada penelitian ini juga membuat model transportasi dengan asumsi semua alat transportasi mendistribusikan produk tahu ke pasar yang sama. Adapun representasi jaringan pada pendistribusian produk tahu di Pabrik Tahu Tufik adalah sebagai berikut.

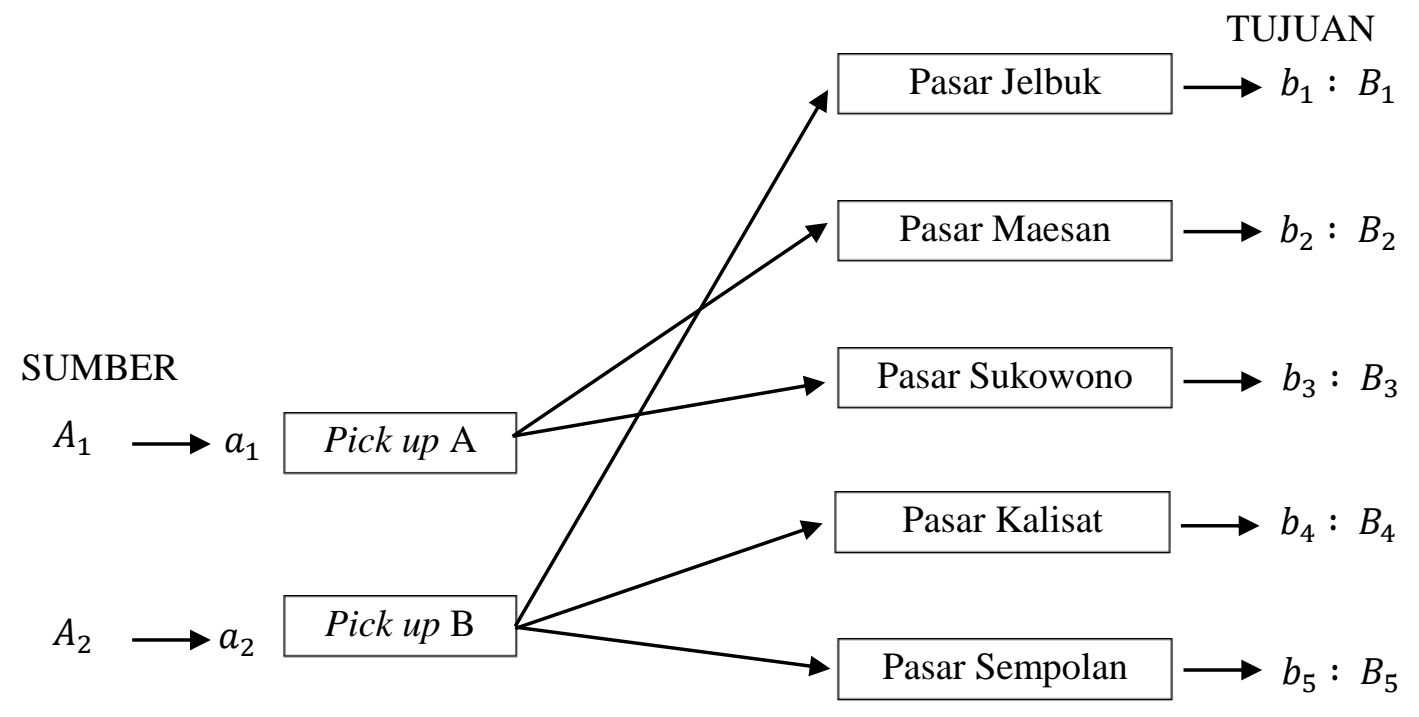


Gambar 1. Representasi Jaringan Data Pengiriman Produk (Masalah Setimbang)

Keterangan:

$A_{1}=$ Sumber 1 (pick up A)

$A_{2}=$ Sumber 2 (pick up B)

$a_{1}=$ Jumlah persediaan produk dari sumber pick up $A$

$a_{2}=$ Jumlah persediaan produk dari sumber pick up $B$

$B_{1}=$ Pasar Jelbuk

$B_{2}=$ Pasar Maesan

$B_{3}=$ Pasar Sukowono

$B_{4}=$ Pasar Kalisat

$B_{5}=$ Pasar Sempolan

$C=$ Biaya transportasi produk tahu per papan dari sumber ke tujuan

Model transportasi dapat ditentukan dengan mencari biaya transportasi per papan tahu terlebih dahulu menggunakan rumus berikut.

$$
C=\frac{c_{t}+c_{T t}}{Q}
$$

Dengan:

$C=$ Biaya transportasi per papan

$c_{t}=$ Biaya Tetap

$c_{T t}=$ Biaya Tidak Tetap

$Q=$ Bayak Permintaan

Biaya tetap merupakan biaya yang dikeluarkan oleh pabrik untuk proses pendistribusian yang nilainnya tidak berubah atau tetap dan tidak dipengaruhi olaeh faktor lain. Biaya tetap pada penelitian ini adalah gaji sopir, gaji kernet, dan biaya perawatan. Sedangkan biaya tidak tetap merupakan biaya yang dikeluarkan oleh pabrik untuk proses pndistribusian yang nilainya berubah atau tidak tetap karena adanya beberapa faktor yang mempengaruhi. Biaya tidak tetap yaitu biaya Bahan Bakar Minyak (BBM) untuk masingmasing lokasi pasar yang dipengaruhi oleh jarak tempuh, jenis kendaraan, dan banyak permintaan. Berikut hasil pehitungan biaya transportasi per papan tahu untuk permasalahan setimbang.

Tabel 1. Biaya Transportasi per papan untuk Permasalahan Setimbang

\begin{tabular}{|c|c|c|c|c|c|c|}
\hline \multirow{2}{*}{ Sumber } & \multicolumn{5}{|c|}{ Tujuan } & \multirow{2}{*}{ Persediaan } \\
\hline & $B_{1}$ & $B_{2}$ & $B_{3}$ & $B_{4}$ & $B_{5}$ & \\
\hline Pick Up A & 0 & 5271 & 5466 & 0 & 0 & 409 \\
\hline Pick Up B & 10036 & 0 & 0 & 914 & 2979 & 1618 \\
\hline Permintaan & 101 & 220 & 189 & 1180 & 337 & 2027 \\
\hline
\end{tabular}


Dari hasil perhitungan, Total Persediaan $=$ Total Permintaan, sehingga model transportasi dari tabel tersebut adalah sebagai berikut.

Fungsi Tujuan:

Minimum $Z=5271 X_{12}+5466 X_{13}+10036 X_{21}+914 X_{24}+2979 X_{25}$

Fungsi Kendala:

$X_{11}+X_{12}+X_{13}+X_{14}+X_{15}=409$

$X_{21}+X_{22}+X_{23}+X_{24}+X_{25}=1618$

$X_{11}+X_{21}=101$

$X_{12}+X_{22}=220$

$X_{13}+X_{23}=189$

$X_{14}+X_{24}=1180$

$X_{15}+X_{25}=337$

$X_{11}, X_{12}, X_{13}, X_{14}, X_{15}, X_{21}, X_{22}, X_{23}, X_{24}, X_{25} \geq 0$

Sedangkan hasil perhitungan biaya transportasi per papan tahu untuk permasalahan tidak setimbang adalah sebagai berikut.

Tabel 2. Biaya Transportasi per papan untuk Permasalahan Tidak Setimbang

\begin{tabular}{|c|c|c|c|c|c|c|}
\hline \multirow{2}{*}{ Sumber } & \multicolumn{5}{|c|}{ Tujuan } & \multirow{2}{*}{ Persediaan } \\
\hline & $B_{1}$ & $B_{2}$ & $B_{3}$ & $B_{4}$ & $B_{5}$ & \\
\hline Pick Up A & 2010 & 4575 & 5100 & 2097 & 2008 & 1849 \\
\hline Pick Up B & 9789 & 673 & 648 & 870 & 2931 & 4586 \\
\hline Permintaan & 101 & 220 & 189 & 1180 & 337 & 2027 \\
\hline
\end{tabular}

Dari hasil perhitungan, Total Persediaan $\geq$ Total Permintaan, sehingga model transportasi dari tabel tersebut adalah sebagai berikut.

Fungsi Tujuan:

Minimum

$$
\begin{aligned}
Z=2010 X_{11}+ & 4575 X_{12}+5100 X_{13}+2097 X_{14}+2008 X_{15}+9789 X_{21}+673 X_{22} \\
& +648 X_{23}+870 X_{24}+2931 X_{25}
\end{aligned}
$$

Fungsi Kendala:

$X_{11}+X_{12}+X_{13}+X_{14}+X_{15}+X_{16} \leq 1849$

$X_{21}+X_{22}+X_{23}+X_{24}+X_{25}+X_{26} \leq 4586$

$X_{11}+X_{21} \geq 101$

$X_{12}+X_{22} \geq 220$

$X_{13}+X_{23} \geq 189$

$X_{14}+X_{24} \geq 1180$

$X_{15}+X_{25} \geq 337$

$X_{11}, X_{12}, X_{13}, X_{14}, X_{15}, X_{16}, X_{21}, X_{22}, X_{23}, X_{24}, X_{25}, X_{26} \geq 0$

Model transportasi dari studi kasus distribusi di Pabrik Tahu Taufik pada permasalahan setimbang dan tidak setimbang yang telah terbentuk kemudian diselesaikan 
dengan menggunakan MVAM. Setelah menemukan hasil dengan menggunakan MVAM, kemudian model transportasi pada permasalahan setimbang dan tidak setimbang diselesaikan menggunakan metode simpleks dengan aplikasi QM for Windows V5 untuk mencari solusi optimal.

Hasil perhitungan yang diperoleh dengan menggunakan MVAM dibandingkan dengan solusi optimal metode simpleks, kemudian divalidasi dengan biaya riil yang dikeluarkan oleh pabrik untuk proses pendistribusian. Teknik validasi pada penelitian ini disebut dengan metode triangulasi. Metode triangulasi adalah metode pemeriksaan data yaitu membandingkan data dengan yang lain sebagai pengecekan [2]. Jika jumlah iterasi dan hasil solusi yang diperoleh dari penyelesaian MVAM pada permasalahan transportasi setimbang maupun tidak setimbang lebih sedikit atau sama dengan jumlah iterasi dan hasil perhitungan dari metode simpleks, maka perhitungan menggunakan MVAM lebih baik dan efisien. Selanjutnya hasil tersebut dibandingkan dengan biaya riil yang dikeluarkan oleh pabrik, jika hasil dari perhitungan MVAM dan solusi optimal metode simpleks lebih kecil dari biaya riil maka model transportasi tersebut dinyatakan valid.

Tabel 3. Perbandingan Hasil yang Diperoleh

\begin{tabular}{lll}
\hline No. & \multicolumn{1}{c}{ Metode } & $\begin{array}{c}\text { Biaya Transportasi } \\
\text { yang dihasilkan }\end{array}$ \\
\hline 1. & Modified Vogel's Approximation Method (MVAM) & \\
& Masalah Setimbang & $R p 1.164 .911,00$ \\
& Masalah Tidak Setimbang & $R p 2.176 .838,00$ \\
2. $\quad$ Solusi Optimal Metode Simpleks & \\
& Masalah Setimbang & $R p 1.164 .911,00$ \\
& Masalah Tidak Setimbang & $R p 2.176 .838,00$ \\
3. $\quad$ Biaya Riil Pabrik & $R p 2.472 .692,00$
\end{tabular}

\section{Kesimpulan}

Berdasarkan penelitian tersebut, model transportasi dapat ditentukan dengan mencari biaya transportasi per papan tahu menggunakan rumus berikut.

$$
C=\frac{c_{t}+c_{T t}}{Q}
$$

Hasil perhitungan biaya transportasi menggunakan Modified Vogel's Approximation Method (MVAM) memberikan biaya transportasi sama dengan solusi optimal metode simpleks, baik untuk masalah setimbang maupun tidak setimbang dan lebih baik daripada perhitungan biaya yang dikeluarkan oleh pabrik serta hanya memerlukan sedikit iterasi. Adapun saran yang diberikan adalah perhitungan pada penelitian ini dapat dijadikan pedoman untuk meminimumkan biaya transportasi distribusi oleh pihak pabrik.

\section{Daftar Pustaka}


[1] Amelia, Lenti. 2018. Penyelesaian Masalah Transportasi Menggunakan Metode Approksimasi Vogel Modifikasi (MVAM) dan Improved Zero Point Method (IZPM). Bandung: UIN Sunan Gunung Djati.

[2] Moleong, L. J. 2012. Metode Penelitian Kualitatif. Bandung: Remaja Radakarya.

[3] M.Wali Ullah, M. Alhaz Uddin, dan Rijwana Kawser. 2016. "A Modified Vogel's Approximation Method for Obtaning a Good Primal Solutioa of Transportation Problems". Annals of Pure and Applied Mathematics. 64-65.

[4] Taha, Hamdy A. 2003. Operator Research: An Introduction (7 th Edition). USA: Pearson Education.

[5] Tjiptono, Fandy. 2008. Manajemen Pemasaran dan Pemasaran Jasa, Edisi Revisi. Bandung: Alfabeta. 